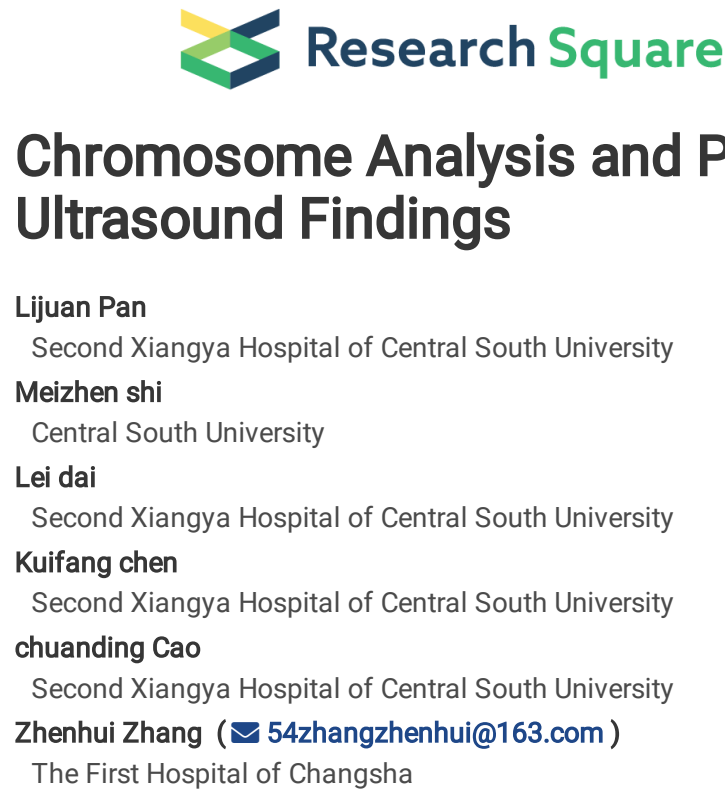

\title{
Chromosome Analysis and Postnatal Follow-Up of Fetuses With Abnormal Ultrasound Findings
}

Research Article

Keywords: fetal abnormalities, ultrasound, follow-up, chromosome analysis, copy number variations, chromosome microarray analysis, copy number variations sequencing

Posted Date: January 13th, 2021

DOI: https://doi.org/10.21203/rs.3.rs-139022/v1

License: (c) (i) This work is licensed under a Creative Commons Attribution 4.0 International License. Read Full License 


\section{Abstract}

Objective-To analyze the correlation between copy number variations (CNVs) and prenatal ultrasound abnormalities, characterize the CNVs in diverse prenatal phenotypes, and provide detailed follow-up results for prenatal diagnosis.

Method-The results obtained in 1152 fetuses referred for chromosome testing due to different ultrasound anomalies were analyzed. CNV detection was performed by chromosomal microarray analysis (CMA) and copy number variation sequencing (CNV-seq). The postnatal outcomes of the fetuses were followed up.

Result-Chromosomal abnormalities were detected in 149 of 1152 pregnancies (12.9\%), including 84 (7.3\%) macroscopic and 65 (5.6\%) submicroscopic anomalies. The highest proportion of chromosomal defects was found in fetuses with hydrops (38.5\%), followed by fetuses with multiple abnormalities (32.1\%). The most common CNV number variation was $22 q 11$ deletion ( $0.7 \%)$, followed by $17 q 12$ deletion $(0.4 \%)$ and $15 q 11.2$ deletion $(0.4 \%)$. Bilateral hyperechogenic kidneys were identified in all fetuses with the $17 q 12$ deletion, and all cases of $15 q 11.2$ deletion were positive only for soft markers. On postnatal follow-up of 362 live births, 2 cases of esophageal atresia and 2 cases of craniosynostosis were found that were not accurately diagnosed by prenatal ultrasound.

Conclusion-we identified chromosomal abnormalities in approximately one eight of the pregnancies with abnormal ultrasound findings. More emphasis should be placed on the improvement of prenatal detection of esophageal atresia and craniosynostosis.

\section{Introduction}

Fetal structural abnormalities are found in approximately $3 \%$ of pregnancies ${ }^{1}$. Ultrasonography can identify fetal abnormalities ranging from a single minor defect to severe multisystem anomalies. They may be associated with chromosomal aneuploidy or copy number variants (CNVs). Chromosomal microarray $(C M)^{2,3}$, and CNV sequencing (CNV-Seq) ${ }^{4,5}$ have been increasingly adopted in prenatal diagnosis to detect submicroscopic pathogenic copy number variations (PCNVs). The addition of CMA testing to karyotyping increases the frequency of detection of chromosomal abnormalities by $3-5 \%{ }^{2,3}$.

Certain CNVs correlate with specific prenatal phenotypes ${ }^{6-9}$. The frequency of chromosomal anomalies varies with the specific structural anomaly and the number of ultrasound-detected defects. However, more data are needed to clarify the correlation between CNVs and prenatal abnormalities. Moreover, the follow-up studies of the cases with a congenital abnormality are frequently restricted to a single disease ${ }^{10-12}$; therefore, these results may not be generalizable. In our study, samples of 1152 fetuses with various ultrasound findings were analyzed by CMA and CNV-Seq to determine the correlation between CNVs and prenatal ultrasound abnormalities, including soft makers and structural anomalies. Additionally, we conducted a detailed follow-up of fetuses with abnormal ultrasound findings to gain information for prenatal diagnosis.

\section{Materials And Methods}

\section{Patients and Ultrasonography}

Our study included 1152 pregnant women who received fetal chromosome examination by CMA or CNV-seq tests due to abnormal ultrasonographic findings, including positive soft markers and structural anomalies. The women were admitted to the Xiangya Hospital of Central South University and Hunan Jiahui Genetic Hospital between January 2013 and June 2019. All pregnant couples provided written informed consent. The mean gestational age of mothers was 28.2 years (range, 22-45 years), and the mean age of fetuses at the invasive procedure was 20.3 weeks (range, 11-37 weeks). The study was approved by the Medical Ethics Committee of Xiangya Hospital of Central South University and Hunan Jiahui Genetic Hospital.

All methods were performed in accordance with Medical Ethics Committee of Xiangya Hospital of Central South University and Hunan Jiahui Genetic Hospital.

Ultrasound scanning of fetuses was performed between 11 and 35 weeks of gestation. The positive soft markers included screening for thickened nuchal translucency or nuchal fold (greater than 95th percentile), absence or dysplasia of nasal bone, short long bones (more than 2 SDs below the mean), hyperechogenic bowel, tricuspid regurgitation, mild ventricular expansion (10-15mm), intracardiac echogenic focus, choroid plexus cyst, single umbilical artery, enlarged cisterna magna (10-15mm), hydronephrosis ( $>4 \mathrm{~mm}$ before 28 weeks, $>7 \mathrm{~mm}$ after 28 weeks), persistent left superior vena cava, and aberrant right subclavian artery. Fetal structural anomalies were categorized into 10 phenotypic classes based on their location, including the cardiovascular system, central nervous system, genitourinary system, musculoskeletal, gastrointestinal, respiratory, facial, abdominal wall system, hydrops fetalis, and multiple malformations involving two or more systems [Supplement 1].

\section{Sample Collection and Preparation}

Fetal DNA was obtained from amniotic fluid, cord blood, or fetal skin. The genomic DNA was prepared using the DNeasy Blood and Tissue Kit (Qiagen, Hilden, Germany). The quality and concentration of genomic DNA in the samples were assessed by agarose gel electrophoresis and a NanoDrop spectrophotometer (Thermo Fisher Scientific, Wilmington, DE, USA).

\section{SNP Array Analysis and CNV-seq}

Chromosome CNV analysis was used before 2017 and was performed using the HumanCytoSNP-12 BeadChip array (Illumina, San Diego, CA, USA), which comprises about 300,000 SNP probes with an average marker spacing of approximately one probe every $10 \mathrm{~kb}$. CNV-seq was used from 2017 and utilized the HiSeq 2000 platform (Illumina). All sequencing procedures were performed as previously described $4,13,14$. 
Copy number variations (CNVs) were called at an effective minimal resolution of $100 \mathrm{~kb}$ involving at least 10 contiguous probes.

The CNVs were classified based on their size. CNVs $\geq 10 \mathrm{Mb}$ were defined as chromosomal macroscopic anomalies, which could be identified by traditional karyotyping. By contrast, CNVs $<10 \mathrm{Mb}$ were defined as chromosomal microscopic anomalies (microdeletions/microduplications).

Detected CNVs were evaluated based on a review of scientific literature and the following public databases: Database of Genomic Variants (http://projects.tcag.ca/variation/), DECIPHER (http://decipher.sanger.ac.uk/), UCSC (http://genome.ucsc.edu/), and OMIM (http://www.ncbi.nlm.nih.gov/omim). Variants of uncertain significance (VOUS), and pathogenic CNVs. CNVs coinciding with known polymorphic CNVs reported in multiple peer-reviewed publications or databases as benign variants were considered benign. Conversely, CNVs were defined as pathogenic if 1 ) the CNV was documented as clinically significant in multiple peer-reviewed publications, regardless of its penetrance and expressivity, or 2) the CNV overlapped a smaller interval with clearly established clinical significance, or 3 ) the CNV was $>5 \mathrm{Mb}$ long and no well-established cytogenetic heteromorphisms were present in this region. CNVs that did not fit any of the above criteria were considered as VOUS.

\section{Parental study}

If CNVs were detected in the fetus, parental samples were subsequently analyzed by karyotyping or FISH, according to the CNV result. Routine G-banding karyotyping was performed using standard methods. The FISH analysis was performed using commercially available subtelomeric specific probes (VYSIS, Inc., Downers Grove, IL, USA) according to the manufacturer's protocols.

\section{Postnatal Follow-up and Statistical Analysis}

Follow-up was conducted by phone calls. The median time of follow-up was 10 months (range 3-24). The follow-up content based on medical reports included gestational age at birth, age, height, weight, physical exam results, large motor skills development, and other positive results. The correspondence between the postnatal exam and prenatal ultrasound was defined as an agreement (same diagnosis), additional (additional findings undetected by ultrasound), or unconfirmed (false positive and false negative ultrasound results). Categorical data are presented as numbers and proportions. Comparison between groups was performed using the Chi-square test. A $P$-value of $<0.05$ was considered statistically significant. All statistical analyses were done using the SPSS 16.0 software (SSPS, Chicago, IL, USA).

\section{Results}

\section{Chromosome Analysis}

Fetal chromosome examination using CMA or CNV-seq tests was performed in 1152 fetuses with abnormal ultrasonographic findings, including 405 positive soft markers and 747 structural anomalies. The analysis employed CMA in 367 cases and CNV-seq in 785 cases. Fetal DNA was obtained from amniotic fluid in $880(76.4 \%)$ fetuses, skin samples after pregnancy termination in $212(18.4 \%)$ fetuses, and cord blood in 60 (5.2\%) fetuses.

Chromosomal abnormalities were detected in 149 (12.9\%) samples, involving 84 (7.3\%) macroscopic anomalies and 65 (5.6\%) submicroscopic anomalies (Table 1). The frequency of chromosome macroscopic anomalies was significantly higher in hydrops fetuses (35.7\%) than in the remaining cohort. While multiple abnormalities (13.9\%) are most common in copy number variations, followed by the central nervous system (7.9\%) and musculoskeletal system (7.3\%).

Table 1

Distribution of copy number variants by ultrasonographic anomaly

\begin{tabular}{|c|c|c|c|c|c|c|c|c|c|c|}
\hline & Total & Cardiovascular & CNS & GU & GI & $\begin{array}{l}\text { Fetal } \\
\text { hydrops }\end{array}$ & $\begin{array}{l}\text { Musculo- } \\
\text { skeletal }\end{array}$ & $\begin{array}{l}\text { Abdominal } \\
\text { wall }\end{array}$ & Facial & Respirat \\
\hline$n$ & 1152 & $192(16.7 \%)$ & $89(7.7 \%)$ & $106(9.2 \%)$ & $37(3.2 \%)$ & $70(6.1 \%)$ & $41(3.6)$ & $24(2.1 \%)$ & $35(3.0 \%)$ & 16(1.4\%, \\
\hline $\begin{array}{l}\text { Total } \\
\text { chromosome } \\
\text { abnormalities }\end{array}$ & $149(12.9 \%)$ & $22(11.4 \%)$ & $9(10.1 \%)$ & $9(8.5 \%)$ & $0(0 \%)$ & $27(38.5 \%)$ & $3(7.3 \%)$ & $0(0 \%)$ & $2(5.7 \%)$ & $0(0 \%)$ \\
\hline $\begin{array}{l}\text { Macroscopic } \\
\text { anormalies }\end{array}$ & $84(7.3 \%)$ & $11(5.7 \%)$ & $2(2.2 \%)$ & $3(2.8 \%)$ & $0(0 \%)$ & 25(35.7\%) & $0(0 \%)$ & $0(0 \%)$ & $0(0 \%)$ & $0(0 \%)$ \\
\hline $\begin{array}{l}\text { Submicroscopic } \\
\text { anomalie }\end{array}$ & $65(5.6 \%)$ & $11(5.7 \%)$ & $7(7.9 \%)$ & $6(5.7 \%)$ & $0(0 \%)$ & $2(2.8 \%)$ & $3(7.3 \%)$ & $0(0 \%)$ & $2(5.7 \%)$ & $0(0 \%)$ \\
\hline PCNV & $33(2.9 \%)$ & $6(3.1) \% \rrbracket$ & $2(2.3 \%)$ & $4(3.8 \%)$ & $0(0 \%)$ & $1(1.4 \%)$ & $2(4.9 \%)$ & $0(0 \%)$ & $0(0 \%)$ & $0(0 \%)$ \\
\hline LpCNV & $32(2.7 \%)$ & $5(2.6 \%)$ & $5(5.6 \%)$ & $2(1.9 \%)$ & $0(0 \%)$ & $1(1.4 \%)$ & $1(2.4 \%)$ & $0(0 \%)$ & $2(8.6 \%)$ & $0(0 \%)$ \\
\hline Vous & $206(17.9 \%)$ & $36(18.7 \%)$ & $24(26.9 \%)$ & $15(14.1 \%)$ & $16(43.2 \%)$ & $7(10.0 \%)$ & $10(24.4 \%)$ & $3(12.5 \%))$ & $3(8.6 \%)$ & $4(25 \%)$ \\
\hline
\end{tabular}

CNS, central nervous system; GU, genitourinary; GI, gastrointestinal; PCNV, pathogenic copy number variant; LpCNV, likely pathogenic copy number variant.; $V$ significance

Among the 84 chromosomal macroscopic anomalies, the three most common were trisomy 21,18 , and $45 \mathrm{X}$, which comprised $77 \%$ of all karyotype-detectable aberrations. The prenatal ultrasound showed multiple malformations in $65 \%$ of fetuses with trisomy 18 , and hydrops fetalis in $64.7 \%$ of cases with $45 \mathrm{X}$. 
Among the 65 pathogenic and likely pathogenic CNVs, 22q11 deletion ( 9 cases, $0.7 \%$ ) was the most common, followed by $17 q 12$ deletion ( 5 cases, $0.4 \%$ ) and $15 q 11.2$ deletion ( 5 cases, $0.4 \%$ ). Of note, bilateral hyperechogenic kidneys were found in all $17 q 12$ deletion fetuses, and in all $15 q 11.2$ deletion cases only soft markers were positive (Table 2). However, both ultrasound manifestations (hyperechogenic kidneys and soft markers) corresponded to benign phenotypes. The five cases of $15 q 11.2$ deletion syndrome included 4 cases of the termination of pregnancy for $15 q 11.2$ deletion and 1 case that was found to have craniosynostosis after birth with significant global developmental delay.

Table 2

QUltrasonographic Anomaly of the three most common copy number variants

\begin{tabular}{|c|c|c|c|c|c|c|}
\hline $\mathrm{n}$ & CNV position [hg19] & $\begin{array}{l}\text { Size } \\
(\mathrm{Mb})\end{array}$ & Ultrasound & methods & $\begin{array}{l}\text { Parental } \\
\text { study }\end{array}$ & interpretation \\
\hline 1 & $\begin{array}{l}\text { arr22q11.21(18,874,965- } \\
21,464,479) \times 1\end{array}$ & 2.6 & Thickened nuchal fold & CMA & de novo & \multirow[t]{9}{*}{$\begin{array}{l}22 q 11 \text { deletion associated } \\
\text { with DiGeorge syndrome }\end{array}$} \\
\hline 2 & $\begin{array}{l}\text { arr22q11.21(18,844,632- } \\
21,800,444) \times 1\end{array}$ & 2.9 & $\begin{array}{l}\text { Unilateral ureteral } \\
\text { dilatation,Hydronephrosis,VSD } \llbracket \text { aortic stenosis } \\
\text { single umbilical artery, }\end{array}$ & CMA & de novo & \\
\hline 3 & $\begin{array}{l}\text { arr22q11.21(18,847,953- } \\
21,855,411) \times 1\end{array}$ & 3.0 & $\begin{array}{l}\text { IAA,VSD Uunilateral renal agenesis } \square \text { Unilateral } \\
\text { ureteral dilatation, ureterocele }\end{array}$ & CMA & de novo & \\
\hline 4 & $\begin{array}{l}\text { arr22q11.21(18,895,703- } \\
21,462,353) \times 1\end{array}$ & 2.6 & Clubfeet,Oligohydramnios & CMA & de novo & \\
\hline 5 & $\begin{array}{l}\text { arr22q11.21(18,856,942 - } \\
21,736,471) \times 1\end{array}$ & 2.88 & Truncus arteriosus,VSD Right aortic arch & CMA & de novo & \\
\hline 6 & $\begin{array}{l}\text { seq[hg19] } \\
22 q 11.21(18.92 \mathrm{Mb}- \\
21.48 \mathrm{Mb}) \times 1\end{array}$ & 2.56 & Single umbilical artery & CNV-seq & de novo & \\
\hline 7 & $\begin{array}{l}\text { seq[hg19]22q11.21(18.92 Mb- } \\
21.92 \mathrm{Mb}) \times 1\end{array}$ & 3.0 & Truncus arteriosus,VSD Right aortic arch & CNV-seq & de novo & \\
\hline 8 & $\begin{array}{l}\text { seq[hg19] 22q11.21(18.9 Mb- } \\
21.46 \mathrm{Mb}) \times 1\end{array}$ & 2.56 & Complex congenital heart disease & CNV-seq & de novo & \\
\hline 9 & $\begin{array}{l}\text { seq[hg19] 22q11.21(18.9 Mb- } \\
21.46 \mathrm{Mb}) \times 1\end{array}$ & 2.56 & Complex congenital heart disease & CNV-seq & de novo & \\
\hline \multirow[t]{2}{*}{10} & \multirow{2}{*}{$\begin{array}{l}\text { arr17q12(34815551- } \\
\text { 36351076)x1 }\end{array}$} & \multirow[t]{2}{*}{1.5} & Hyperechogenic kidneys & \multirow[t]{2}{*}{ CMA } & \multirow{2}{*}{$\begin{array}{l}\text { maternal } \\
\text { inherited }\end{array}$} & \multirow[t]{10}{*}{ 17q12 deletion syndrome } \\
\hline & & & Enlarged kidney & & & \\
\hline \multirow[t]{2}{*}{11} & \multirow{2}{*}{$\begin{array}{l}\text { seq[hg19] 17q12(34.84 Mb- } \\
36.26 \mathrm{Mb}) \times 1\end{array}$} & \multirow[t]{2}{*}{1.42} & Hyperechogenic kidneys & \multirow[t]{2}{*}{ CNV-seq } & \multirow[t]{2}{*}{ de novo } & \\
\hline & & & Enlarged kidney & & & \\
\hline \multirow[t]{2}{*}{12} & \multirow{2}{*}{$\begin{array}{l}\text { seq[hg19] 17q12(34.84 Mb- } \\
36.26 \mathrm{Mb}) \times 1\end{array}$} & \multirow[t]{2}{*}{1.42} & Polycystic kidney & \multirow[t]{2}{*}{ CNV-seq } & \multirow[t]{2}{*}{ de novo } & \\
\hline & & & Oligohydramnios & & & \\
\hline \multirow[t]{2}{*}{13} & \multirow{2}{*}{$\begin{array}{l}\text { seq[hg19] 17q12(34.82 Mb- } \\
36.26 \mathrm{Mb}) \times 1\end{array}$} & \multirow[t]{2}{*}{1.44} & Hyperechogenic kidneys & \multirow[t]{2}{*}{ CNV-seq } & \multirow[t]{2}{*}{ de novo } & \\
\hline & & & Clubfeet & & & \\
\hline \multirow[t]{2}{*}{14} & \multirow{2}{*}{$\begin{array}{l}\text { seq[hg19] 17q12(34.8 Mb- } \\
36.5 \mathrm{Mb}) \times 1\end{array}$} & \multirow[t]{2}{*}{1.7} & Hyperechogenic kidneys & \multirow[t]{2}{*}{ CNV-seq } & \multirow[t]{2}{*}{ de novo } & \\
\hline & & & Unilateral renal cyst & & & \\
\hline 15 & $\begin{array}{l}\operatorname{arr15q11.2(21974835-} \\
23226254) \times 1\end{array}$ & 1.3 & Thickened nuchal translucency & CMA & de novo & \multirow[t]{5}{*}{ 15q11.2deletion syndrome } \\
\hline 16 & $\begin{array}{l}\text { seq[hg19] 15q11.2(23.6 Mb- } \\
29.14 \mathrm{Mb}) \times 1\end{array}$ & 5.54 & Thickened nuchal translucency & CNV-seq & de novo & \\
\hline 17 & $\begin{array}{l}\text { seq[hg19] 15q11.2(22.76 Mb- } \\
23.1 \mathrm{Mb}) \times 1\end{array}$ & 0.34 & Ventriculomegaly & CNV-seq & de novo & \\
\hline 18 & $\begin{array}{l}\text { seq[hg19] } 15 \mathrm{q} 11.2(22.76 \mathrm{Mb}- \\
23.08 \mathrm{Mb}) \times 1\end{array}$ & 0.32 & Short long bones & CNV_seq & de novo & \\
\hline 19 & $\begin{array}{l}\text { seq[hg19] 15q11.2(22.76 Mb- } \\
23.1 \mathrm{Mb}) \times 1\end{array}$ & 0.34 & Choroid plexus cyst & CNV-seq & de novo & \\
\hline
\end{tabular}

The rate of chromosomal abnormalities in the soft markers group was $8.1 \%$ (4.4\% corresponded to macroscopic anomalies and $3.7 \%$ to submicroscopic anomalies), which was significantly lower than in the structural abnormalities group $(15.5 \%, P<0.001)$. Fetal structural anomalies were categorized into 10 phenotypic classes based on their location. The number of cases in these classes ranged from 16 (respiratory) to 192 (cardiovascular). The rate of chromosomal abnormality varied by the anatomical systems involved: the greatest fraction of chromosomal abnormalities were found in fetuses with 
hydrops (38.5\%), multiple malformations (32.1\%), cardiovascular (11.4\%), and central nervous system (10.1\%) anomalies, followed by the genitourinary (8.5\%), skeletal (7.3\%), and facial (5.7\%) anomalies; the other systems were negative.

\section{Follow-up Results}

Pregnancy outcomes were available for $533(46.3 \%)$ of the 1152 fetuses. Of these, 165 (30.9\%) were pregnancies that parents opted for termination and 6 (1.1\%) died in the uterus. Additionally, there were $12(2.3 \%)$ postnatal deaths, and $350(65.7 \%)$ live births. Postnatal findings confirmed prenatal ultrasound in $96.9 \%$ fetuses (351/362), provided additional information in $4(1.1 \%)$ fetuses, and did not confirm prenatal ultrasound in 7 (1.9\%) fetuses. The additional findings undetected by ultrasound include 2 cases of esophageal atresia ( 1 with cleft palate) and 2 cases of prenatal craniosynostosis. The missed findings were 4 ventricular septal defects, and only soft markers were detected by prenatal ultrasound. The instances of misdiagnosis included 1 case of clubfoot (found to be normal after birth), 1 abdominal lymph cyst (diagnosed postnatally as intestinal atresia), and 1 duplex kidney (found to be normal after birth) (Table 3).

Table 3

Postnatal findings inconsistent with prenatal ultrasonography

\begin{tabular}{|c|c|c|c|c|}
\hline $\begin{array}{l}\text { Case } \\
\text { number }\end{array}$ & Prenatal ultrasound findings & Postnatal diagnosis & CMA or CNV-seq & Outcome \\
\hline 1 & Microphthalmia & $\begin{array}{l}\text { Microphthalmia, esophageal atresia, esophagotracheal } \\
\text { fistula, chondrodysplasia of larynx, ASD }\end{array}$ & Normal & $\begin{array}{l}\text { Live } \\
\text { birth }\end{array}$ \\
\hline 2 & VSD, black cyst & $\begin{array}{l}\text { VSD, black cyst, esophageal atresia, esophagotracheal } \\
\text { fistula }\end{array}$ & Normal & $\begin{array}{l}\text { Infantile } \\
\text { death }\end{array}$ \\
\hline 3 & $\begin{array}{l}\text { VSD, mild ventricular } \\
\text { expansion, spinal anomaly }\end{array}$ & VSD, spinal anomaly, craniosynostosis, cleft palate & $\begin{array}{l}\text { VOUS } \\
\text { seq[hg19]17q21.1q21.2(38.16 Mb- } \\
38.66 \mathrm{Mb}) \times 3\end{array}$ & $\begin{array}{l}\text { Live } \\
\text { birth }\end{array}$ \\
\hline 4 & Mild ventricular expansion & Craniosynostosis & $\begin{array}{l}\text { Pathology } \\
\text { seq[hg19] 15q11.2(22.76 Mb- } \\
23.1 \mathrm{Mb}) \times 1\end{array}$ & $\begin{array}{l}\text { Live } \\
\text { birth }\end{array}$ \\
\hline 5 & Single umbilical artery & Ventricular septal defects & Normal & $\begin{array}{l}\text { Live } \\
\text { birth }\end{array}$ \\
\hline 6 & Short long bones & Ventricular septal defects & Normal & $\begin{array}{l}\text { Live } \\
\text { birth }\end{array}$ \\
\hline 7 & $\begin{array}{l}\text { Aberrant right subclavian } \\
\text { artery }\end{array}$ & Ventricular septal defects & $\begin{array}{l}\text { Vous } \\
\text { seq[hg19]8p23.2(2.58 Mb- } \\
2.92 \mathrm{Mb}) \times 3\end{array}$ & $\begin{array}{l}\text { Live } \\
\text { birth }\end{array}$ \\
\hline 8 & Tricuspid regurgitation & Ventricular septal defects & $\begin{array}{l}\text { Vous } \\
\text { seq[hg19]1q23.3(162.08 Mb- } \\
162.36 \mathrm{Mb}) \times 3\end{array}$ & $\begin{array}{l}\text { Live } \\
\text { birth }\end{array}$ \\
\hline 9 & Clubfoot & Normal & Normal & $\begin{array}{l}\text { Live } \\
\text { birth }\end{array}$ \\
\hline 10 & Abdominal lymph cyst & Intestinal atresia & $\begin{array}{l}\text { Vous } \\
\text { seq[hg19]Xp22.33(3.44 Mb- } \\
3.74 \mathrm{Mb}) \times 2\end{array}$ & $\begin{array}{l}\text { Live } \\
\text { birth }\end{array}$ \\
\hline 11 & Duplex kidney & Normal & $\begin{array}{l}\text { Vous } \\
\text { seq[hg19] 8q23.3(115.78 Mb- } \\
116.28 \mathrm{Mb}) \times 3\end{array}$ & $\begin{array}{l}\text { Live } \\
\text { birth }\end{array}$ \\
\hline
\end{tabular}

\section{Discussion}

In our study, chromosomal abnormalities were detected in $12.9 \%$ of pregnancies, $7.3 \%$ were macroscopic anomalies and $5.6 \%$ were submicroscopic anomalies. The rate of chromosomal abnormalities associated with structural defects (15.5\%) is consistent with previous studies, which identified significant chromosomal abnormalities in $16 \%$ of fetuses in which ultrasonography indicated at least one anomaly ${ }^{15}$. The frequency of chromosomal abnormalities in fetuses with soft markers (8.1\%) was higher than reported in other studies (approximately $4 \%$ ). This difference may be due to the following reasons: 1 ) at our referral center, many pregnant women with positive soft markers are of advanced age and have a complicated pregnancy, and 2) our study included fetuses with persistent left superior vena cava and aberrant right subclavian artery. Although the rate of chromosomal abnormalities in the soft markers group was lower than in the structural abnormalities group, identifying an additional $4.4 \%$ pathogenic or likely pathogenic CNV can avert the possibility of birth of children with a chromosome microdeletion or microduplication syndrome. Certainly, the risk of pregnancy loss or other post-amniocentesis complications should be considered, even if currently the risk related to amniocentesis is approximately 1 in $800^{16}$. 
The rate of chromosomal abnormalities varied among the anatomical systems involved. We detected chromosomal abnormalities more frequently in association with fetal hydrops, multiple malformations, cardiovascular and central nervous anomalies, and, to a lesser extent, abnormalities of the genitourinary and musculoskeletal systems. In a recent study using WES to identify genetic variants in fetuses with structural anomalies, the greatest proportion of variants was found in cases of hydrops ${ }^{17}$. Their relative frequency can give insight into the proportion of anomalies, such as hydrops fetalis, that potentially have a detectable underlying genetic cause.

Certain CNVs are associated with specific phenotypes. For example, cardiovascular abnormalities represent one of the pillars of clinical diagnosis of $22 q 11.2$ deletion (DiGeorge syndrome). In our study, $50 \%$ of cases with $22 q 11$ deletion syndrome exhibited cardiovascular defects. Bilateral hyperechogenic kidneys were found in all fetuses with 17q12 deletion, which is in line with previous studie ${ }^{\mathrm{s} 18}$. The 15q11.2 BP1-BP2 deletion has been associated with variable phenotypes and low penetrance. Our results tend to suggest that the deletion confers milder phenotypes, as only soft markers were positive prenatally. A previous investigation documented that the $15 q 11.2$ deletion is associated with congenital cardiovascular malformations ${ }^{19}$, but no such case was present in our study. There are some controversies regarding the classification of $15 q 11.2$ deletion in prenatal management. Marshall et al. ${ }^{20}$ recommended classifying the deletion as "pathogenic of mild effect size, while Maya et $\mathrm{al}^{21}$. recommended that $15 \mathrm{q} 11.2$ deletion should not be considered pathogenic and should not be reported to the parents in the prenatal setting. In our laboratory, this deletion is classified as pathogenic variation with incomplete penetrance. Unfortunately, among the 5 cases of $15 q 11.2$ deletion syndrome, in 4 instances the termination of pregnancy was chosen based on the report of pathogenic copy number variant, and 1 case was found after birth to have craniosynostosis with a significant global developmental delay. 15q11.2 BP1-BP2 structural variation is associated with changes in in brain morphology and cognition ${ }^{22}$, possibly indicating that this CNV is more commonly associated with neurocognitive impairment than with structural anomalies. Larger studies of prenatal and postnatal phenotypic groups will be required to provide useful information for interpreting and consulting cases with 15q11.2 deletions.

Follow-up results demonstrated a high agreement between prenatal ultrasound and living birth. Not surprisingly, the most frequently missed prenatal diagnosis was the ventricular septal defect. Also, esophageal atresia and craniosynostosis are difficult to diagnose by ultrasound prenatally. Analysis of the prenatal ultrasound images of these patients revealed that 2 cases of craniosynostosis had abnormal head morphology (1 occipital flattening, 1 navicular head). However, since both fetuses had multiple malformations, the doctors focused on the obvious structural abnormalities and ignored the changes in cranial morphology. Therefore, alterations in cranial morphology provide an important clue that requires consideration to exclude the possibility of craniosynostosis.

The antenatal detection rate of esophageal atresia has been extremely poor even in expert hands, with a sensitivity ranging from 40 to $60 \%{ }^{23,24}$. Remarkably, in our study, 2 cases in which esophageal atresia was missed in prenatal ultrasound had co-existent esophagotracheal fistula, making a correct prenatal diagnosis more challenging. More recently, Dall'Asta et al. ${ }^{25}$ demonstrated that the detection of esophageal atresia is possible when three-dimensional ultrasound and Crystal Vue rendering techniques are used. Thus, employing the most current ultrasound methods may increase the accuracy of prenatal detection of esophageal atresia.

Limitations of our study include a high rate of lost follow-up (telephone number errors or refusal to answer). Additionally, many pregnant women do not consent to the autopsy of the fetus due to cultural norms, and the prenatal structural abnormalities could not be confirmed. The absence of data regarding the inheritance (i.e., parental vs. de novo) of each alteration and the presence of many variants of unknown significance increased the difficulty of genetic counseling.

In summary, we identified chromosomal abnormalities in approximately one eight of the pregnancies with abnormal ultrasound findings.. Follow-up is recommended in the management of fetal structural anomalies since it confirms, modifies, or adds information to prenatal diagnosis.

\section{Declarations}

\section{Acknowledgments}

We thank all the patient's family members for their participation and support in this study.

\section{Funding}

This work was supported by grants from the Natural Science Foundation of Hunan Province,China (2020JJ5917).

\section{Competing interests}

There are no potential conflicts of interest to report for this paper.

\section{Availability of data and materials}

The datasets used and/or analysed during the current study available from the corresponding author on reasonable request.

\section{Ethics approval and consent to participate}

The study was approved by the Medical Ethics Committee of Xiangya Hospital of Central South University and Hunan Jiahui Genetic Hospital. All methods were performed in accordance with Medical Ethics Committee of Xiangya Hospital of Central South University and Hunan Jiahui Genetic Hospital.

\section{Consent for publication}




\section{Authors' contributions}

LP, MS, LD and KC design the experiment and perform the experiments. LP, MS, CC and ZZ analyzed the data. LP, ZZ, MS, LD and KC wrote the manuscript. ZZ supervised the whole study.

\section{References}

1. Persson M, Cnattingius S, Villamor E, Soderling J, Pasternak B, Stephansson O, et al. Risk of major congenital malformations in relation to maternal overweight and obesity severity: cohort study of 1.2 million singletons. BMJ. 2017;357:j2563.

2. Wapner RJ, Martin CL, Levy B, Ballif BC, Eng CM, Zachary JM, et al. Chromosomal microarray versus karyotyping for prenatal diagnosis. N Engl J Med. 2012;367:2175-2184.

3. Robson SC, Chitty LS, Morris S, Verhoef T, Ambler G, Wellesley DG, et al. Evaluation of Array Comparative genomic Hybridisation in prenatal diagnosis of fetal anomalies: a multicentre cohort study with cost analysis and assessment of patient, health professional and commissioner preferences for array comparative genomic hybridisation. Efficacy and Mechanism Evaluation. Southampton (UK)2017.

4. Liang D, Peng Y, Lv W, Deng L, Zhang Y, Li H, et al. Copy number variation sequencing for comprehensive diagnosis of chromosome disease syndromes. J Mol Diagn. 2014;16:519-526.

5. Hillman SC, Pretlove S, Coomarasamy A, McMullan DJ, Davison EV, Maher ER, et al. Additional information from array comparative genomic hybridization technology over conventional karyotyping in prenatal diagnosis: a systematic review and meta-analysis. Ultrasound Obstet Gynecol. 2011;37:6-14.

6. Maya I, Singer A, Baris HN, Goldberg Y, Shalata A, Khayat M, et al. Prenatal microarray analysis in right aortic arch-a retrospective cohort study and review of the literature. J Perinatol. 2018;38:468-473.

7. Sagi-Dain L, Maya I, Falik-Zaccai T, Feingold-Zadok M, Lev D, Yonath H, et al. Isolated fetal horseshoe kidney does not seem to increase the risk for abnormal chromosomal microarray results. Eur J Obstet Gynecol Reprod Biol. 2018;222:80-83.

8. Sagi-Dain L, Maya I, Peleg A, Reches A, Banne E, Baris HN, et al. Microarray analysis in pregnancies with isolated unilateral kidney agenesis. Pediatr Res. 2018;83:825-828.

9. Sagi-Dain L, Singer A, Hadid Y, Sharony R, Vinkler C, Bar-Shira A, et al. Non-visualization of fetal gallbladder in microarray era - a retrospective cohort study and review of the literature. J Matern Fetal Neonatal Med. 2019;32:2643-2648.

10. Perlman S, Borovitz Y, Ben-Meir D, Hazan Y, Nagar R, Bardin R, et al. Prenatal diagnosis and postnatal outcome of anterior urethral anomalies. Prenat Diagn. 2019.

11. Moaddab A, Sananes N, Hernandez-Ruano S, Werneck Britto IS, Blumenfeld Y, Stoll F, et al. Prenatal Diagnosis and Perinatal Outcomes of Congenital Megalourethra: A Multicenter Cohort Study and Systematic Review of the Literature. J Ultrasound Med. 2015;34:2057-2064.

12. van Nisselrooij AEL, Rozendaal L, Linskens IH, Clur SA, Hruda J, Pajkrt E, et al. Postnatal outcome of fetal isolated ventricular size disproportion in the absence of aortic coarctation. Ultrasound Obstet Gynecol. 2018;52:593-598.

13. Liang D, Lv W, Wang H, Xu L, Liu J, Li H, et al. Non-invasive prenatal testing of fetal whole chromosome aneuploidy by massively parallel sequencing. Prenat Diagn. 2013;33:409-415.

14. Li H, Durbin R. Fast and accurate short read alignment with Burrows-Wheeler transform. Bioinformatics. 2009;25:1754-1760.

15. Hay SB, Sahoo T, Travis MK, Hovanes K, Dzidic N, Doherty C, et al. ACOG and SMFM guidelines for prenatal diagnosis: Is karyotyping really sufficient? Prenat Diagn. 2018;38:184-189.

16. Wulff CB, Gerds TA, Rode L, Ekelund CK, Petersen OB, Tabor A, et al. Risk of fetal loss associated with invasive testing following combined first-trimester screening for Down syndrome: a national cohort of 147,987 singleton pregnancies. Ultrasound Obstet Gynecol. 2016;47:38-44.

17. Petrovski S, Aggarwal V, Giordano JL, Stosic M, Wou K, Bier L, et al. Whole-exome sequencing in the evaluation of fetal structural anomalies: a prospective cohort study. Lancet. 2019;393:758-767.

18. Jing XY, Huang LY, Zhen L, Han J, Li DZ. Prenatal diagnosis of 17q12 deletion syndrome: a retrospective case series. J Obstet Gynaecol. 2019;39:323327.

19. Li X, Shi G, Li Y, Zhang X, Xiang Y, Wang T, et al. 15q11.2 deletion is enriched in patients with total anomalous pulmonary venous connection. J Med Genet. 2020.

20. Marshall CR, Howrigan DP, Merico D, Thiruvahindrapuram B, Wu W, Greer DS, et al. Contribution of copy number variants to schizophrenia from a genomewide study of 41,321 subjects. Nat Genet. 2017;49:27-35.

21. Maya I, Perlman S, Shohat M, Kahana S, Yacobson S, Tenne T, et al. Should We Report 15q11.2 BP1-BP2 Deletions and Duplications in the Prenatal Setting? J Clin Med. 2020;9.

22. Silva Al, Ulfarsson MO, Stefansson H, Gustafsson O, Walters GB, Linden DEJ, et al. Reciprocal White Matter Changes Associated With Copy Number Variation at 15q11.2 BP1-BP2: A Diffusion Tensor Imaging Study. Biol Psychiatry. 2019;85:563-572.

23. de Jong EM, de Haan MA, Gischler SJ, Hop W, Cohen-Overbeek TE, Bax NM, et al. Pre- and postnatal diagnosis and outcome of fetuses and neonates with esophageal atresia and tracheoesophageal fistula. Prenat Diagn. 2010;30:274-279.

24. Bradshaw CJ, Thakkar H, Knutzen L, Marsh R, Pacilli M, Impey L, et al. Accuracy of prenatal detection of tracheoesophageal fistula and oesophageal atresia. J Pediatr Surg. 2016;51:1268-1272. 
25. Dall'Asta A, Grisolia G, Nanni M, Volpe N, Schera GBL, Frusca T, et al. Sonographic demonstration of fetal esophagus using three-dimensional ultrasound imaging. Ultrasound Obstet Gynecol. 2019;54:746-751.

\section{Supplementary Files}

This is a list of supplementary files associated with this preprint. Click to download.

- Tables1.docx 